\title{
Testing an Optimization-Simulation Model for Optimal Pump and Valve Operations with Required Storage Tank Turnovers
}

\author{
Puneet N. Khatavkar and Larry W. Mays \\ Arizona State University, Tempe, Arizona.
}

\begin{abstract}
An optimization-simulation model is developed for the operation of pumps and valves in water distribution systems (WDS) requiring storage tank turnover. The purpose of the model is to determine the pump and valve operation schedules that minimize the power costs or energy used for pump operations which satisfy demand, pressure, and tank turnover requirements. The modeling approach interfaces a genetic algorithm optimization procedure with the WDS hydraulic and water quality simulator (EPANET) in the framework of an optimal control problem. The interfacing of the genetic algorithm and the EPANET model is implemented within the framework of MATLAB. The application of the optimization-simulation model to a physical water distribution system verifies the importance of such an approach for practical applications.
\end{abstract}

\section{Introduction}

\subsection{Water Age and Tank Turnover Rates}

Water distribution storage is provided to ensure the reliability of water supply, maintain pressures, equalize pumping and treatment rates, reduce the size of transmission mains, and improve operational flexibility and efficiency (Walski 2000). Storage of finished drinking water in tanks leads to the degradation of water quality through chemical, physical and biological processes that occur as water ages and through external contamination of water in tanks. Water quality problems associated with storage of finished water in tanks include loss of disinfectant residual, formation of disinfection byproducts, development of flavours and odours, increase in $\mathrm{pH}$, corrosion, buildup of iron and manganese, and the occurrence of hydrogen sulfide and leachate from internal coatings. An implicit objective in both the design and operation of distribution system storage facilities is the minimization of detention time and the avoidance of parcels of water that remain in the storage facility for long periods (Grayman and Kirmeyer 2000). The mean detention time within a reservoir is dependent on the inflow and outflow patterns and the volume of water in the reservoir. The age of water in a tank is governed by the volume of water in the tank that is exchanged during daily operations of the WDS.

Tank turnover is the timely replacement of water stored in a tank through consumptive use and pumping. Timely turnover of the water stored in a tank leads to a reduction in water age and improvement in the water quality. Thus tank turnover rates are an important requirement for efficient operation of a water distribution system (WDS). Water age in storage tanks can be managed through routine turnover through fluctuations in the water levels. Water level fluctuations in a WDS are managed as an integrated operation within pressure zones, demand service areas, and the system as a whole rather than on an individual tank basis (AWWA 2002b). This reference discusses available guidelines used for WDS operations for water turnover rates (summarized in Table 1).

Table 1 Guidelines for tank turnover rates (AWWA 2002b).

\begin{tabular}{|c|c|}
\hline Agency & Guideline \\
\hline 1. Georgia Environmental Protection Division & 1. Daily turnover goal equals $50 \%$ of storage \\
\hline (AWWA 2002b). & facility volume; minimum desired turnover equals \\
\hline & $30 \%$ of storage facility volume. \\
\hline 2. Virginia Department of Health, Water Supply & 2. Complete turnover recommended every $72 \mathrm{~h}$. \\
\hline \multicolumn{2}{|l|}{ Engineering Division, Richmond, VA. (AWWA } \\
\hline $2002 b)$ & \\
\hline 3. Ohio EPA. & 3. Required daily turnover of $20 \%$. Recommended \\
\hline 4. U.S. Navy (1999). & $\begin{array}{l}\text { daily turnover of } 25 \% \text {. } \\
\text { 4. Daily turnover of } 1 / 3 \text { of total storage. }\end{array}$ \\
\hline
\end{tabular}

The research described herein presents a novel method to control WDS pumps and valves for tank turnover considerations which could be used to optimize the operation of WDS pumps and valves as well as for the design of new WDS tanks.

\subsection{Previous Optimization Models for Pump Operation}

Goldman et al. (2002) provide a detailed list of optimization models developed for pump operations. Models optimizing pump operations in water distribution systems (WDS) developed after 2002 include: Rao and Salomons (2007); Sakarya and Mays (2000); Salomons et al. (2007); Shamir and Salomons (2008); Ramos and Ramos (2009); Cohen et al. (2009); Costa et al. (2010); Kurek and

Khatavkar, Puneet N. and Larry W. Mays. 2019. "Testing an Optimization-Simulation Model for Optimal Pump and Valve Operations with Required Storage Tank Turnovers." Journal of Water Management Modeling 27: C464. doi: 10.14796/JWMM.C464.

(C) CHI 2019. www.chijournal.org ISSN 2292-6062. 
Ostfeld (2013); Goldman et al. (2002); Hashemi et al. (2014); Ghaddar et al. (2015) and Khatavkar and Mays (2017).

A few optimization or simulation models for pump operation have been described in the literature which have been developed as optimization models interfaced with EPANET (Rossman 2000). EPANET (developed by the U.S. Environmental Protection Agency, USEPA) is commonly-used open-source software for hydraulic and water quality simulations. Brion and Mays (1991) present a methodology based on solving large scale nonlinear programming using an optimization-simulation interface. Ormsbee et al. (1994) provide a detailed literature review for various optimization-simulation models for pump controls. Sakarya and Mays (2000) developed a model using nonlinear programming interfaced with EPANET for both water quality and hydraulic performance requirements. Goldman and Mays (2005) developed a method that linked simulated annealing with the EPANET model to find optimal pump operation for WDS while meeting both water quality and hydraulic performance requirements. Ozger and Mays (2005) interfaced a simulated annealing model with EPANET for determining the optimal location of isolation valves in water distribution systems for security purposes. Broad et al. (2005) and Salomons et al. (2007) used a surrogate hydraulic model (or meta-model), trained to approximate the nonlinear hydraulic equations using a machine learning approach, which is a support vector machine that replaces EPANET.

Kang and Lansey (2010) described a method for real-time scheduling of valve operation and booster disinfection to improve systemwide water quality for known pump operation schedules. The optimization-simulation methodology is based upon linking the EPANET model with a genetic algorithm. Costa et al. (2010) developed a branch-and-bound algorithm interfaced with EPANET for optimal pump operation of WDS. Kurek and Ostfeld (2013) linked EPANET to a multi-objective methodology using a strength Pareto evolutionary algorithm to demonstrate the tradeoffs between pumping cost, water quality and tank sizing of WDS. Khatavkar and Mays (2018) presented a model for the real-time operation of water distribution systems under limited electrical power availability with consideration for water quality. This method also links the EPANET model with a genetic algorithm.

The main novelty of this paper is to consider valve controls along with pump controls. The model presented in this paper embraces tank volume turnover requirements and tank level set points which are important considerations for WDS operations and have never been considered in previous studies.

\section{Mathematical Formulation of Optimiza- tion Model}

An optimization model is used to determine the pump and valve operation schedules in order to minimize the total power costs or energy usage for pump operations that satisfy demands, keep nodal pressure within bounds, and satisfy tank turnover require- ments. The optimization model for pump and valve operations is formulated for a water distribution system (WDS) with $K$ nodes, $M$ pipes, Pu pumps and S tanks. The decision variables for the model include binary control variables for pumps $\left(X_{p, t}=0\right.$ for pump $p$ switched off at time $t$ and $X_{p, t}=1$ for pump $p$ switched on) and inflow valve controls $\left(X_{i n(s, t)}=0\right.$ for input valve to tank $s$ closed at time $t$ and 1 for valve open) and outflow valve controls $\left(X_{\text {out(s,t) }}=0\right.$ for output valve from tank $s$ closed at time $t$ and 1 for valve open) for tanks in the WDS.

\section{Objective Function}

The total power costs for pumping in a WDS are computed using the following objective function (Obj) to minimize the power and costs of pumping:

$$
\begin{array}{r}
\text { Minimize } O b j=\sum_{p=1}^{p=P u} \sum_{t=1}^{t=T}\left[X_{p, t} \frac{\varnothing_{t} Q_{p, t} H_{p, t}}{3956 \eta_{p, t}}\right] \\
\forall p=1, \ldots, P u \text { and } t=1, \ldots, T
\end{array}
$$

where:

$$
\begin{aligned}
p & =\text { index for pumps, } \\
t & =\text { index for time, } \\
\varnothing_{t} & =\text { price of power at time } t(\$ / \mathrm{HP}), \\
Q_{p, t} & =\text { flow through pump } p \text { at time } t(\mathrm{gpm}), \\
\eta_{p, t} & =\text { total dynamic head for pump } p \text { at time } \mathrm{t}(\mathrm{ft}), \text { and } \\
h_{p u, t} & =\text { efficiency of pump } p \text { at time } t .
\end{aligned}
$$

The objective function $\mathrm{Obj}$ is subject to the constraints described in the following subsections.

\section{Equations Solved Implicitly by EPANET for Hydraulic}

\section{Analysis}

The distribution of flow throughout the network must satisfy the principles of conservation of mass and conservation of energy which are defined as hydraulic constraints. The conservation of mass at each junction node, assuming water is an incompressible fluid, is:

$$
\begin{aligned}
& \sum_{i}\left(Q_{i, k}\right)_{t}-\sum_{j}\left(Q_{k, j}\right)_{t}-Q_{k, t}=0 \\
& \forall k=1, \ldots, K \text { and } t=1, \ldots, T
\end{aligned}
$$

where:

$$
\begin{aligned}
\left(\mathrm{Q}_{i, k}\right)_{t}= & \text { flow in the pipe } \mathrm{m} \text { connecting nodes } i \text { and } k \text { at } \\
& \text { time } t \text { (gpm), and } \\
\mathrm{Q}_{k, t}= & \text { flow consumed (or supplied) at node } k \text { at time } t \\
& \text { (gpm); }
\end{aligned}
$$

The conservation of energy for each pipe $m$ connecting nodes $i$ and $j$ in the set of all pipes $M$ is:

$$
\begin{array}{r}
H_{i, t}-H_{j, t}=f\left(Q_{i, j}\right)_{t} \\
\forall i, j \in K \text { and } t=1, \ldots, T
\end{array}
$$

where:

$$
H_{i, t^{\prime}} H_{j, t}=\text { hydraulic heads at consecutive nodes } i \text { and } j \text {. }
$$

The total number of hydraulic constraints is $(K+M) T$ and the total number of unknowns is also $(K+M) T$, which are the 
discharges in $M$ pipes and the hydraulic grade line elevations at $K$ nodes. The pump operation problem is an extended period simulation problem. The height of water stored in a tank $s$ for the current time period $t, y_{s, t}$ is a function of the height of water stored from the previous time period:

$$
y_{s, t}=f\left(y_{s, t-1}\right) \quad \forall s=1, \ldots, S \text { and } t=1, \ldots, T
$$

The bounds on the level of water storage in a tank $s$ for time $t$ are:

$$
\underline{y}_{s} \leq y_{s, t} \leq \bar{y}_{s}
$$

$$
\forall s=1, \ldots, S \text { and } t=1, \ldots, T
$$

where:

$$
\begin{gathered}
\underline{y}_{s^{\prime}} \bar{y}_{s}=\text { lower and upper bounds of the elevation of } \\
\text { water stored in node } s \text { at time } t, y_{s, t} . \\
\text { Equation } 5 \text { imposes lower and upper bounds on tank }
\end{gathered}
$$
levels based on the tank design. These limits are normally due to physical limitations and fire flow storage requirements of the storage tank. The hydraulic constraints given in Equations 1-5 are solved implicitly in the optimization model using EPANET (Rossman 2000) and are documented in detail by Khatavkar and Mays (2018).

\section{Pressure Constraints}

One of the major requirements of WDS operations is to maintain pressures within the mandated bounds to ensure public health and the safety of the WDS components. Lower and upper bounds for the nodal pressures in the WDS are imposed using the following constraint (Khatavkar and Mays 2018):

$$
\underline{P} \leq P_{k, t} \leq \bar{P}
$$

$$
\forall k=1, \ldots, K \text { and } t=1, \ldots, T
$$

where:

$\underline{P}=$ lower bound for nodal pressures in the system, $P_{k, t}=$ pressure at node $k$ and time $t$, and

$\bar{P}=$ upper bound for nodal pressures in the system. Hydraulic heads $\left(H_{i, t}\right)$ at nodes are modeled as a function of flow $\left(Q_{i, j}\right)$ between the nodes in EPANET. Equation 3 represents this relationship used by EPANET between the hydraulic heads and flows. Equation 6 gives the pressure constraint that imposes lower and upper bounds on the nodal pressures within the WDS, which are not imposed in EPANET. Hydraulic head measures the total energy available at a particular node in the WDS including the datum head, velocity head, and pressure head, while the nodal pressures $\left(P_{k, t}\right)$ represent the pressure head in terms of pounds per square inch (psi) or Pascals $(\mathrm{Pa})$.

\section{Tank Level Set Point Constraints}

Water utilities may require the water tanks in a WDS to be filled to a certain required upper level $\left(\overline{y_{\text {req(s) }}}\right)$ and emptied to a certain required lower level $\left(\underline{y_{\text {req(s) }}}\right)$ during a $24 \mathrm{~h}$ operation of the WDS. These set points are required for public health and safety and water age considerations. The constraints for tank level set-point requirements are:

$$
\begin{aligned}
& \max \left(\left[y_{s, t}\right]_{t=0: T-24}^{t=24: T}\right) \geq \overline{y_{\text {req }(s)}} \\
& \forall s=1, \ldots, S \text { and } t=1, \ldots, T \\
& \min \left(\left[y_{s, t}\right]_{t=0: T-24}^{t=24: T}\right) \leq \frac{y_{r e q(s)}}{\forall s=1, \ldots, S \text { and } t=1, \ldots, T}
\end{aligned}
$$

where:

$\overline{y_{\text {req(s) }}}$ and $\underline{y_{\text {req(s) }}}$ = required upper and lower set points for tank levels in the system.

Equation 7 is a constraint that requires the $24 \mathrm{~h}$ maximum water level in a tank to exceed a certain upper set point. Equation 8 is a lower tank level set point constraint that requires the $24 \mathrm{~h}$ minimum water level in the tank to fall below the lower tank level set point.

\section{Tank Turnover Constraints}

Tank turnover can be simply defined as the volume of stored water in a tank replaced through daily consumption use and inflow. The daily consumption use of the stored water in a tank can be determined as the sum of outflows from the tank. This study considers that each water supply tank is provided with an inflow and an outflow valve with binary controls $X_{\text {in }(s, t)}$ and $X_{\text {out }(s, t)} . X_{\text {in }(s, t)}$ and $X_{\text {out(s,t) }}$ take the value 1 when the particular valve is opened and 0 when the valve is closed. The constraints for ensuring the required turnover rate are:

$$
\begin{aligned}
\sum_{t}^{t+24} X_{\text {out }(s, t)} Q_{\text {out }(s, t)} & \geq \theta_{s} \max \left(\left[\operatorname{Vol}_{s, t}\right]_{t}^{T}\right) \\
\forall s & =1, \ldots, S \text { and } t=1, \ldots, T \\
\sum_{t}^{t+24} X_{\text {out }(s, t)} Q_{\text {out }(s, t)} & \leq \sum_{t}^{t+24} X_{\text {in }(s, t)} Q_{\text {in }(s, t)} \\
\forall s & =1, \ldots, S \text { and } t=1, \ldots, T
\end{aligned}
$$

where:

$$
\begin{aligned}
Q_{\text {in }(s, t)^{\prime}} Q_{\text {out(s,t) }} & =\text { inflow and outflow for tank } s \text { at time } t \\
V_{s, t} & =\text { volume of water stored in tank } s \text { at time } t \text {, and } \\
\theta_{s} & =\text { mandated turnover rate for the tank } s .
\end{aligned}
$$

\section{Reduced Optimization Model}

\#The optimization model presented in Equations 1-10 is an optimal control problem solved by interfacing an optimization model (genetic algorithm) with an EPANET simulator. The genetic algorithm scores the various solutions in a solution set with respect to the extent to which the model achieves constraint compliance. The scoring is done through a fitness function (Equation 11) based on a reduced form of the full optimization problem given in Equations 1-10. A reduced optimization model with constraints in the form of penalty functions is solved by the genetic algorithm, which solves unconstrained problems. The reduced optimization model is: 


$$
\begin{aligned}
& \text { Minimize } O b j_{\text {reduced }}=W_{1} \sum_{p=1}^{p-p p_{u}} \sum_{t=1}^{t-T}\left[X_{p, t}, \varnothing_{t} \frac{Q_{p, t} H_{p, t}}{3956 \eta_{p, t}}\right]+ \\
& W_{2} \sum_{k=1}^{k-K} \sum_{t=1}^{t-T}\left[w_{1} \max \left(0,0-P_{k, t}\right)+w_{2} \max \left(0, \underline{P}-P_{k, t}\right)+w_{3} \max \left(0, P_{k, t}-\bar{P}\right)\right]+ \\
& W_{3} \sum_{s=1}^{s-s}\left[\sum_{1}^{T / 24} \max \left(0, \overline{y_{\text {req }(s)}}-\max \left(\left[y_{s, t}\right]_{t-0, T-24}^{t-24: T}\right)\right)+\max \left(0, \min \left(\left[y_{s, t}\right]_{t-0: T-24}^{t-24 . T}\right)-\underline{\left.y_{\text {req }(s)}\right)}\right)\right]+ \\
& W_{4} \sum_{t=1}^{t-T} \sum_{s=1}^{s=S} \max \left(0,\left[\theta \max \left(\left[\operatorname{Vol}_{s, t}\right]_{t}^{T}\right)-\sum_{t}^{t+24} X_{\text {out }(s, t)} Q_{\text {out }(s, t)}\right]\right)
\end{aligned}
$$

where:

$$
\begin{aligned}
O b j_{\text {reduced }}= & \text { reduced objective function, } \\
W_{1}-W_{4}= & \text { penalty weights associated with objective } \\
& \text { function, pressure bounds, tank level bounds, } \\
& \text { and tank volume turnover constraints } \\
& \text { respectively, and } \\
W_{1}-W_{3}= & \text { additional penalty weights for negative } \\
& \text { pressures, lower pressure bound violations, and } \\
& \text { upper pressure bound violations. }
\end{aligned}
$$

The penalty weights $W_{1}-W_{4}$ are determined through sensitivity analysis for each application of the optimization model. The sensitivity analyses are performed for all terms involved in the reduced optimization model (Equation 11). The values of weights to be used for a particular term depend upon the relative importance of the penalty term and the magnitude of the numeric value of the penalty term. Parameters considered for the sensitivity analyses are the value of the objective function, number of pressure bound violations, number of tank level set point violations, and the number of tank volume turnover constraint violations. The optimization model is tested for a range of values for each of the penalty weights. A combination of penalty weights that minimizes the objective function value and has the least number of violations for pressures, tank level set point constraints, and tank volume turnover constraints is chosen for the application.

The penalties $w_{1}, w_{2}$ and $w_{3}$ impose additional weights on lower negative pressures, lower pressure bounds, and upper pressure bounds. EPANET is a demand-driven simulation model that always meets the demands irrespective of pressures at nodes in the WDS. The solutions may have negative pressures at certain nodes for operations where enough water is not pumped to meet the water demands. For every iteration, the GA provides a new set of decision variables (including pump and valve controls) and an EPANET simulation is performed based on the decision variables. A negative pressure penalty function with a large additional penalty weight $w_{1}$ is used in the reduced optimization model to exclude EPANET solutions with negative pressures. The final solution from the optimization-simulation can never include an operation schedule that results in negative pressures.

\section{Model Solution Methodology}

An interface between the genetic algorithm (WDS optimization model) and the EPANET simulator is used to solve the reduced optimization model given in Equation 11. The MATLAB-EPANET interface is created from the open source EPANET-MATLAB toolkit (Eliades 2016). The interface facilitates use of the functionality of EPANET within the MATLAB environment by passing the various commands between the MATLAB mathematical language and the
EPANET simulator. This toolkit was used in conjunction with the genetic algorithm in MATLAB to effect the overall optimizationsimulation methodology shown in Figure 1.

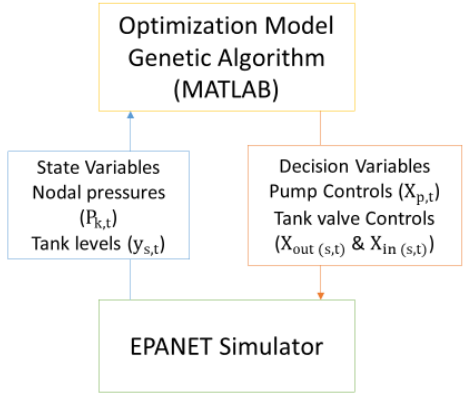

Figure 1 Optimization-simulation methodology.

The genetic algorithm (in MATLAB) searches over the control variable (pump operations $X_{p, t}$ and valve operations $X_{i n(s, t)}$ and $\left.X_{\text {out }(s, t)}\right)$ using the values of the state variables (nodal pressures, pipe flows, water age, and tank levels) determined through an extended time simulation in EPANET. In other words, the optimizer passes pump and valve operations to the simulator which determines the state variables (nodal heads, pipe flows, and tank levels). This process continues until an optimal or near optimal solution is reached.

Basic parameters of the genetic algorithm include population size, number of allowable generations, crossover probability, and mutation probability. Population size defines the total number of solutions (number of times EPANET is solved) in a particular generation. A generation is a set of solutions, from which the next generation is chosen based on crossovers and mutation. A sensitivity analysis was performed to set the genetic algorithm parameters in this study. The combination of parameters giving the best convergence of solution in a minimum computational time was chosen. A population size of 30 was used for the application, with the maximum allowable generations bound at 1000 . The crossover probability and the mutation probability were set at $60 \%$ and $20 \%$. The solutions converged perfectly after 100 generations (3000 function calls) with a computation time of $3650 \mathrm{~s}$.

\section{Example Application}

The example application is the water distribution system (WDS) of city XYZ which has 1427 junctions (nodes), 3 tanks (T-1, T-2 and T-3), 2 treatment plants which are modeled as reservoirs (R-1 and R-2), 1789 pipes, 4 pumps (PMP-1 to PMP-4), 2 pressure release valves (PRV) and 6 flow valves. Figure 2 is a map of the WDS with the locations and details of tanks and pumps in the system. Each tank in the system is given an inflow and an outflow valve. Operation of inflow and outflow valves for the tanks is important for maintaining the required levels in the tanks and for draining the tanks to a certain level on a timely basis to ensure public health and safety. A control valve is provided on the downstream of both the inflow and outflow valves for restraining the direction of flow into and 
out of the tank. The inlet and outflow valves for the tanks can be controlled in four different combinations, as listed in Table 2.

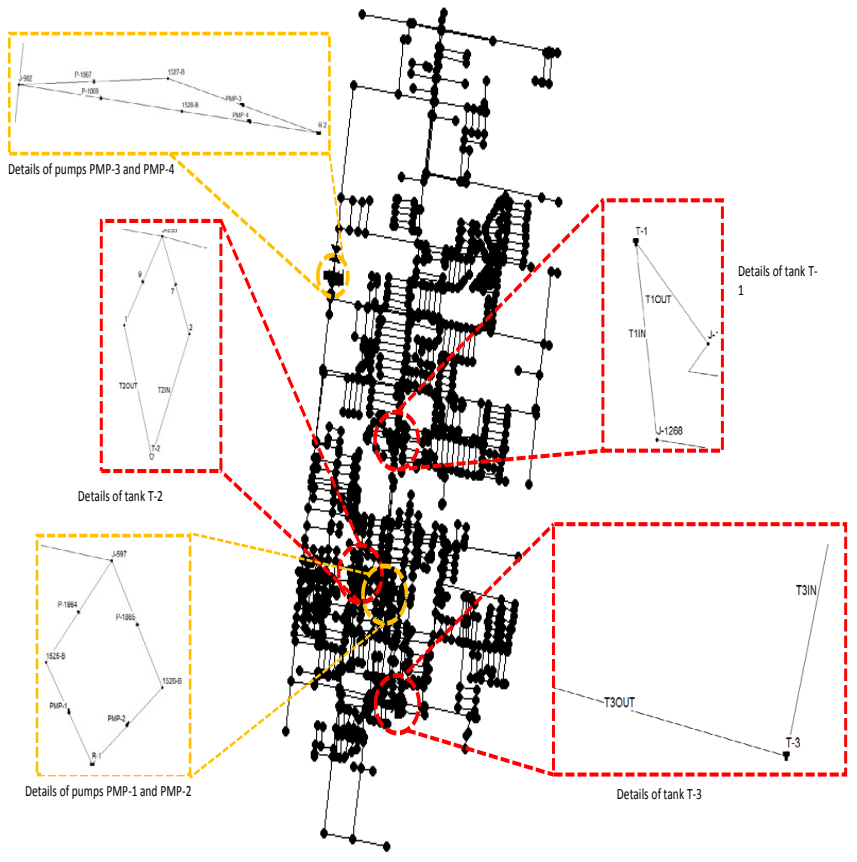

Figure 2 Details of the water distribution system of city XYZ.

Table 2 Control of inflow and outflow valves for tanks.

\begin{tabular}{ccl}
\hline Inflow Valve Status & Outflow Valve Status & \multicolumn{1}{c}{ Flow Condition } \\
\hline 1. Open & 1. Closed & 1. Inflow into the tank. \\
$\begin{array}{c}\text { 2. Closed } \\
\text { 3. Open }\end{array}$ & $\begin{array}{l}\text { 2. Open } \\
\text { 3. Open }\end{array}$ & $\begin{array}{l}\text { 2. Outflow from the tank. } \\
\text { 3. Inflow or outflow depending on the head differ- } \\
\text { ence between the tank and the node downstream of } \\
\text { the valves (depending on the pump operations). }\end{array}$ \\
$\begin{array}{cl}\text { 4. Closed } & \text { 4. Closed flow in or out of the tank. }\end{array}$ \\
\hline
\end{tabular}

Pumps PMP-1 and PMP-2 operate in parallel to pump water from reservoir R1 and pumps PMP-3 and PMP-4 pump water from reservoir R2. Figure 3 shows the pump curves used for the four pumps. The pumps are assumed to operate at $100 \%$ efficiency.
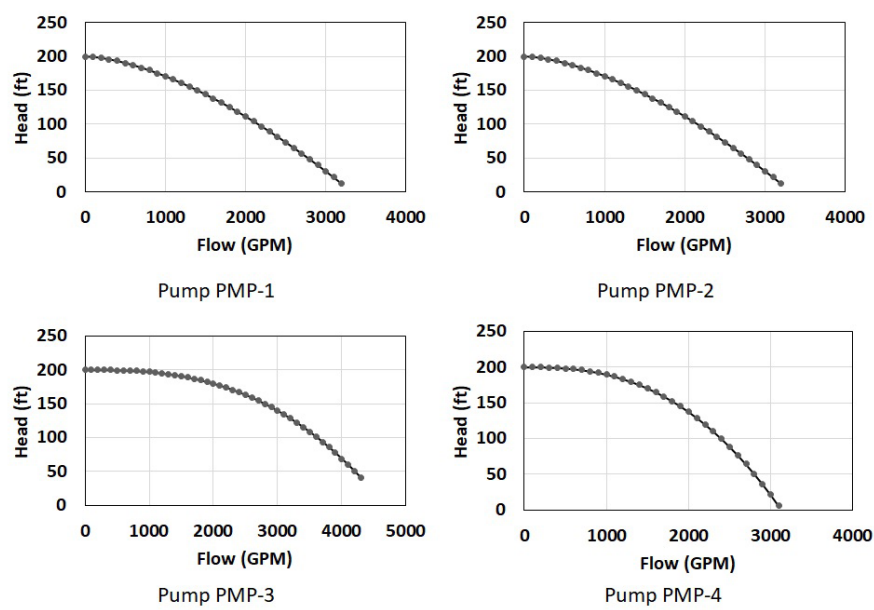

Figure 3 Pump curves.
Tanks T-1 and T-2 are modeled as cylindrical tanks with diameters of $38.5 \mathrm{ft}(11.74 \mathrm{~m})$ and $40 \mathrm{ft}(12.2 \mathrm{~m})$. Both T-1 and $\mathrm{T}-2$ are elevated storage reservoirs with bottom elevations of $205.58 \mathrm{ft}(62.67 \mathrm{~m})$ and $214 \mathrm{ft}(65.23 \mathrm{~m})$. The overflow elevations of tanks T-1 and T-2 are $234 \mathrm{ft}$ (71.32 m) and $244 \mathrm{ft}$ (74.37 m). Tank T-3 is conical at the bottom and the top is nearly cylindrical; it is modeled using a water level-volume curve. Tank T-3 has a bottom elevation of $214.02 \mathrm{ft}(65.23 \mathrm{~m})$ and the overflow elevation of the tank is $251 \mathrm{ft}(76.50 \mathrm{~m})$. The overall demand in the WDS follows a diurnal pattern as shown in Figure 4.

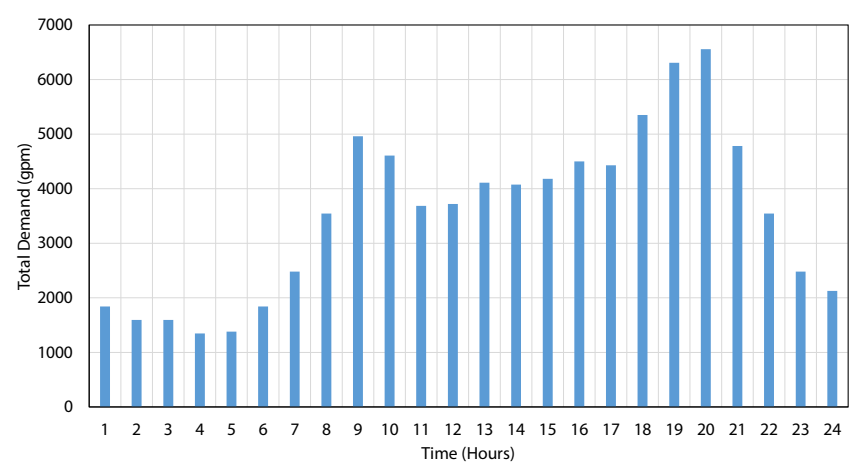

Figure 4 Trends of total demand for city XYZ.

\section{Application Results and Observations}

\subsection{Model Application}

The reduced optimization model, solved by the genetic algorithm (Equation 11), was used for the pump and valve operations of the example system using the optimization-simulation interface outlined in Figure 1. A simulation time of $14 \mathrm{~d}$ ( $336 \mathrm{~h}$ ) was used in EPANET. Two scenarios (both a $25 \%$ and a $40 \%$ turnover rate for WDS operation) were considered for this application, based on the tank turnover guidelines given in Table 2. The lower and upper pressure boundaries for the WDS used to optimize the pump and valve operations were $30 \mathrm{psi}(206.85 \mathrm{kPa})$ and $80 \mathrm{psi}$ (551.58 kPa).

Even though the results use the overflow elevations of the tanks for pump operation, a maximum high water elevation should be established that is less than the overflow elevation for each tank. In normal operation the utility would never want to fill tanks to the overflow elevation, but to some specified maximum high water level a few feet or meters below the overflow elevation. This application did not require emergency storage volumes for each time period but the minimum levels in tank T-3 provide a large emergency storage quantity available throughout each 24 h cycle.

Figure 5 shows the changes in water levels (heads) in the three tanks for a $25 \%$ tank turnover. The tanks fill up during the early hours of the day (off-peak demand hours) and draw down during the later hours of the day. All three tanks fill to the overflow elevations. The $24 \mathrm{~h}$ trends for the simulation were observed 
to cycle (repeat) for a $24 \mathrm{~h}$ simulation period after the third day (72 h) of the application. Keep in mind that a maximum tank operating level would be established for each tank, not allowing it to fill above that level. Figure 6 shows the change of water levels in the three tanks for a $40 \%$ tank turnover. Tanks T-1 and T-2 both fill to their respective overflow elevations and tank T-3 fills to $248 \mathrm{ft}(75.60 \mathrm{~m}), 3 \mathrm{ft}(0.91 \mathrm{~m})$ below the overflow elevation. The elevation of $248 \mathrm{ft}(75.60 \mathrm{~m})$ could be the maximum operating level for tank T-3, to provide a safety margin in the case of altitude failure or other failures that might occur in the system.

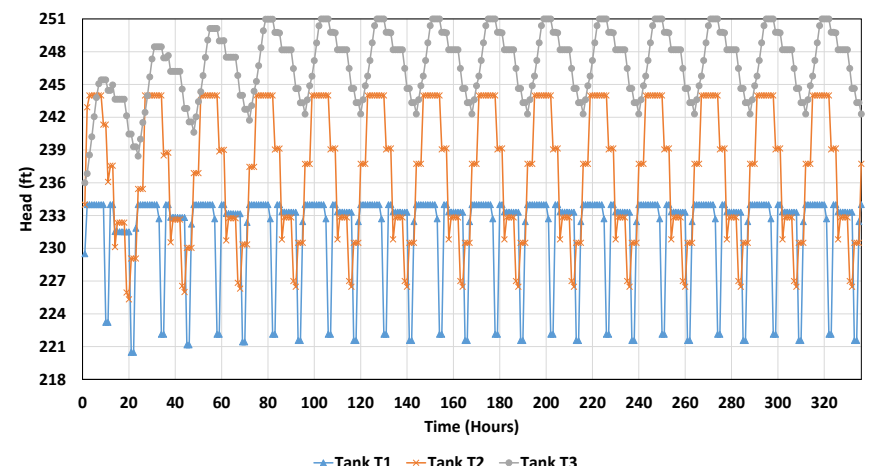

Figure 5 Storage tank levels for $25 \%$ turnover.

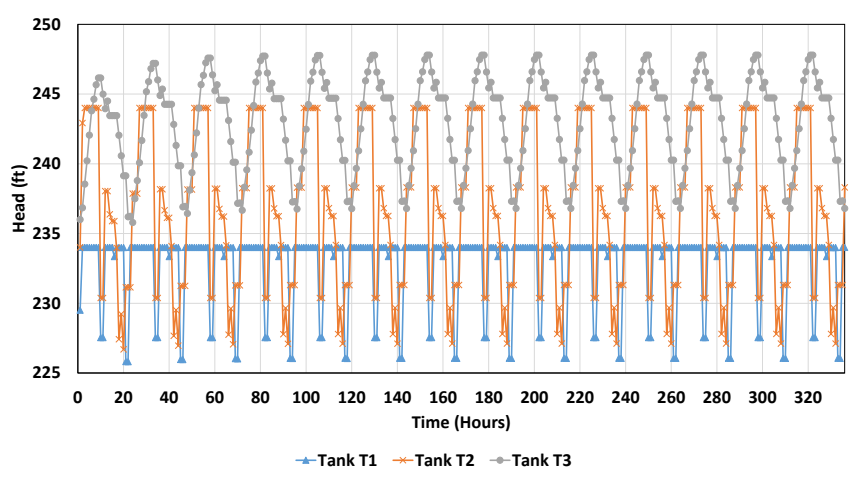

Figure 6 Storage tank levels for $40 \%$ turnover.

Figures 7 and 8 show the trends of water age in the three WDS tanks for the 2 week ( $336 \mathrm{~h}$ ) extended period simulation for the $25 \%$ and $40 \%$ turnover rates. For the $25 \%$ turnover scenario (Figure 7), the highest water age observed during the 2 week simulation is $\sim 90 \mathrm{~h}$ and the water age is seen to be stable after the first week of simulation. For the $40 \%$ turnover, the highest water age observed during the 2 week simulation is $\sim 70 \mathrm{~h}$. The difference between the maximum water ages for the two scenarios shows that the tank turnover requirements can affect the water age in the system. In both the scenarios, the water age in the tank stabilizes within the acceptable limit of $90 \mathrm{~h}$ prescribed by the American Water Works Association (AWWA 2002a). The lower and upper pressure bounds used to optimize the pump and valve operations, $30 \mathrm{psi}(206.84 \mathrm{kPa})$ and $80 \mathrm{psi}(551.58 \mathrm{kPa})$, were satisfied for both the $25 \%$ and $40 \%$ turnovers.

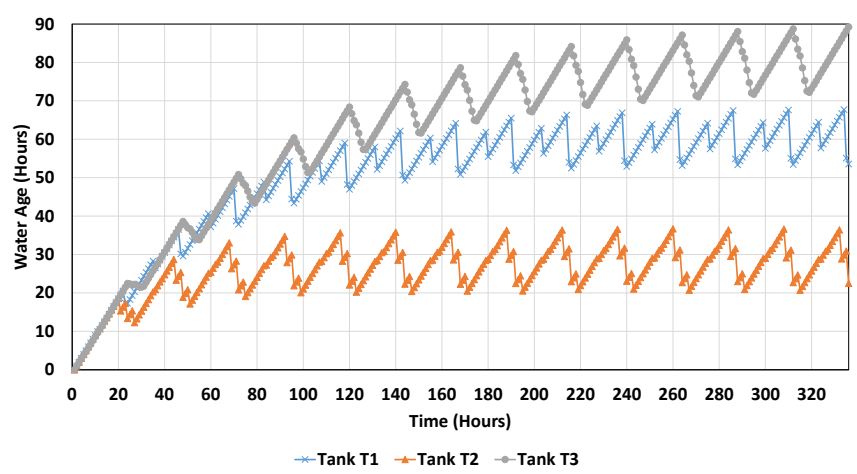

Figure 7 Water age in tanks for $25 \%$ turnover each day.

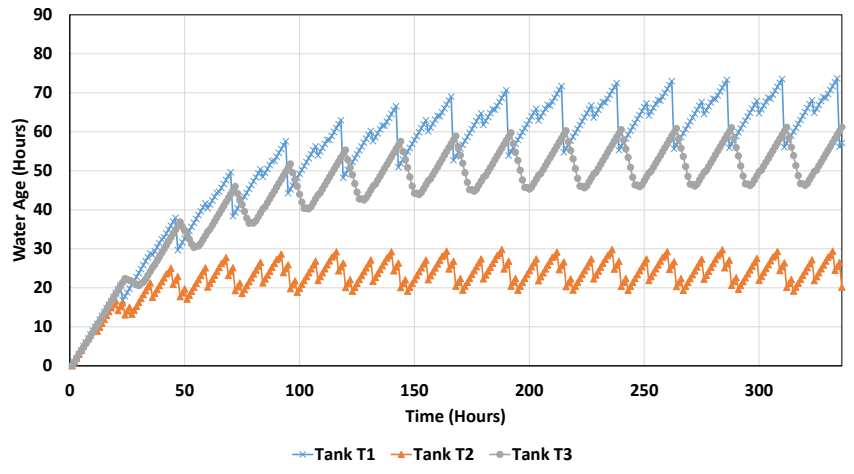

Figure 8 Water age in tanks for $40 \%$ turnover each day.

\subsection{Modifications to WDS of City XYZ}

To further test the new optimization-simulation methodology, the WDS of city XYZ is modified by adding an extra pump (with pump curve similar to pump PMP-4, as shown in Figure 3) and increasing the size of tank T-1 from $38.3 \mathrm{ft}$ (11.67 m) diameter to $68.3 \mathrm{ft}(20.82 \mathrm{~m}$ ) diameter. These modifications are alternatives being considered for the modification of WDS for city XYZ along with the modifications detailed in sections 5.3 and 5.4. The elevations of tank $\mathrm{T}-1$ remain the same with a bottom elevation of $205.58 \mathrm{ft}(62.66 \mathrm{~m})$ and an overflow elevation of $234 \mathrm{ft}(71.32 \mathrm{~m})$. The resulting tank water levels for a $25 \%$ turnover are shown in Figure 9. Water levels in tanks for the optimized operation show that all three tanks fill to their overflow elevations, even though in practice operators would not fill the tanks to that level. It takes $\sim 7 \mathrm{~d}-8 \mathrm{~d}$ for the system to stabilize such that the levels repeat themselves each day. The last $24 \mathrm{~h}$ of operation would be used as the actual operation schedule for the pumps and valves for the $25 \%$ turnover. Water age in the 3 tanks of the modified WDS of city XYZ for a minimum 25\% turnover are shown in Figure 10. Keep in mind that if we did not allow the tanks to fill to the overflow level, but to a lower elevation (e.g. the maximum fill level at $248 \mathrm{ft}, 75.60 \mathrm{~m}$, in tank T-3), then the water ages would be even lower for that tank. 


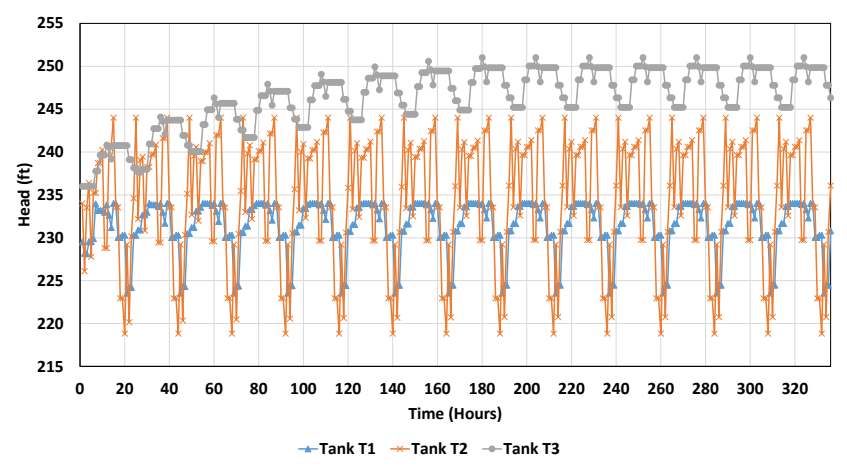

Figure 9 Storage tank levels for $25 \%$ turnover for the modified WDS of city XYZ.

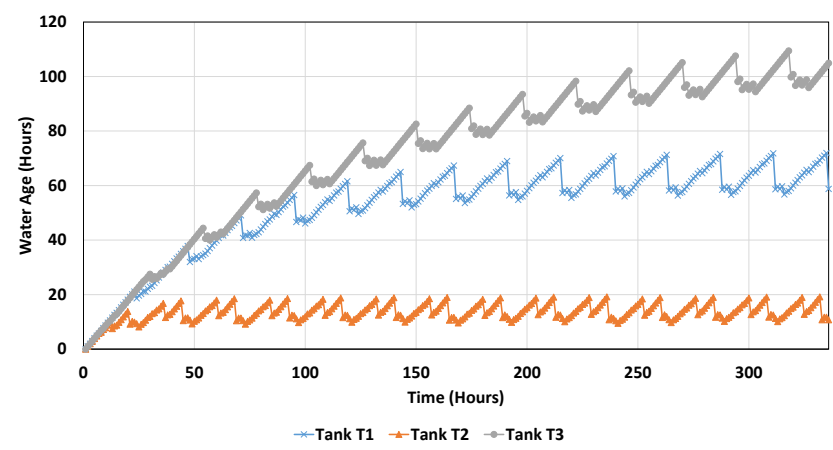

Figure 10 Water age in tanks of the modified WDS of city $\mathrm{XYZ}$ for $25 \%$ turnover each day.

\subsection{Tank T-1 Overflow Elevation Changed to Tank T-3 Elevation}

Both the overflow elevations of tanks T- 1 and T-3 are increased to $251 \mathrm{ft}(76.50 \mathrm{~m})$. A boundary of $25 \%-35 \%$ turnover rates is specified in the optimization. The resulting tank levels are shown in Figure 11 and the water age is shown in Figure 12. Even though we have considered the overflow elevation for the operation of each tank, a lower maximum operating elevation would be used in practice. For example, a maximum operating level for tanks T-1 and T-3 could be set at $248 \mathrm{ft}(75.60 \mathrm{~m})$ and for T- 2 could be set at $241 \mathrm{ft}(73.45 \mathrm{~m})$. This would allow for plenty of emergency storage in the system and would allow for a large turnover.

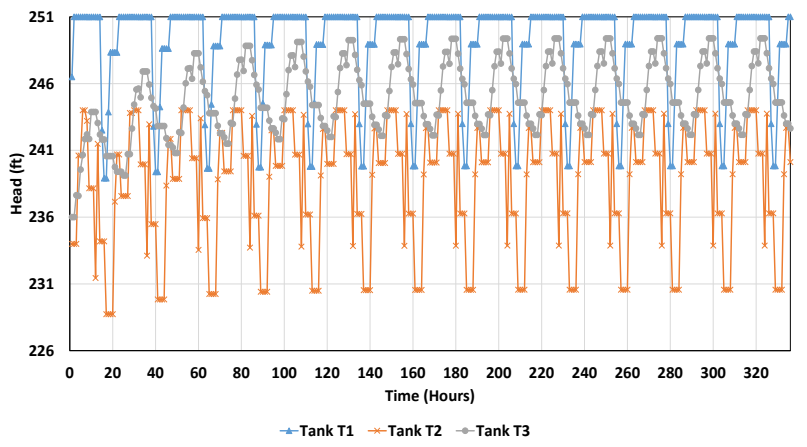

Figure 11 Storage tank levels for a minimum 25\% turnover for the modified WDS of city XYZ with tank T-1 raised to the elevation of tank T-3.

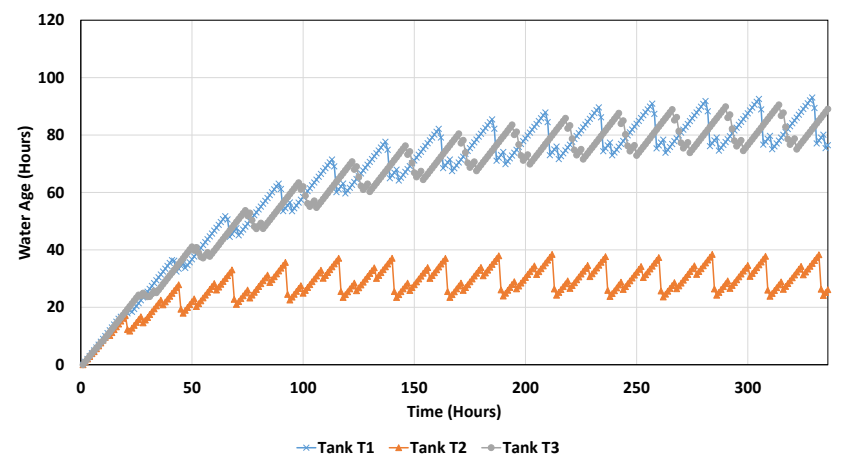

Figure 12 Water age in tanks of the modified city XYZ WDS for a minimum $25 \%$ turnover with tank $\mathrm{T}-1$ raised to the elevation of tank T-3.

All three tanks fill up to their overflow elevations and empty out to the required turnover volume every $24 \mathrm{~h}$ of operation. Tank T-1 filled up to the maximum elevation of $251 \mathrm{ft}(76.50 \mathrm{~m})$. Maximum turnover was observed in tank T-2, followed by tanks $\mathrm{T}-1$ and $\mathrm{T}-2$. All the storage tanks in the system showed a turnover of $\geq 25 \%$ every $24 \mathrm{~h}$ of operation. The water age in the three storage tanks (shown in Figure 12) is under the acceptable limit of $90 \mathrm{~h}$. Larger volume turnovers were observed in tank T-1 as compared to storage levels shown in Figure 9. The water age in tank T-1 (shown in Figure 12) increased in comparison with Figure 10 due to the larger storage volume of the tank. Raising the T-1 overflow elevation to the T-3 elevation provides adequate emergency storage for all three tanks throughout the simulation.

\subsection{Maximum Operating Water Levels Set at 248 $\mathrm{ft}(75.60 \mathrm{~m})$ in Tanks T-1 and T-3}

To make the simulated operation more realistic, the maximum operating water levels were set at $248 \mathrm{ft}$ (75.60 m) in tanks T-1 and $\mathrm{T}-3$. The resulting tank levels for the operations are shown in Figure 13. Note that T-1 and T-3 both fill to the maximum operating levels of $248 \mathrm{ft}(75.60 \mathrm{~m})$. The water age in each of the tanks as a function of time is shown in Figure 14. The results for this application are similar to those observed in Figures 11 and 12 except for the lower maximum water levels in tank T-1 due to the lower maximum operating water level setting. The water age and emergency storages are within acceptable limits throughout the $336 \mathrm{~h}$ simulation.

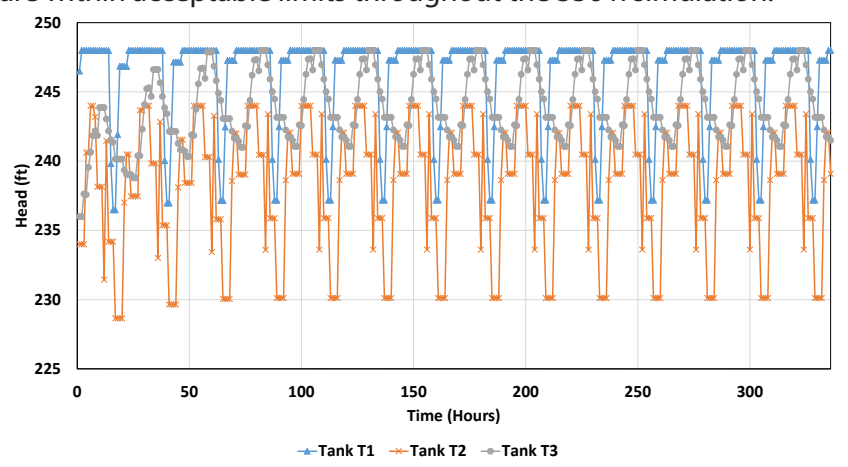

Figure 13 Storage tank levels for maximum operating levels in tanks T-1 and T-3 set at $248 \mathrm{ft}(75.60 \mathrm{~m})$. 


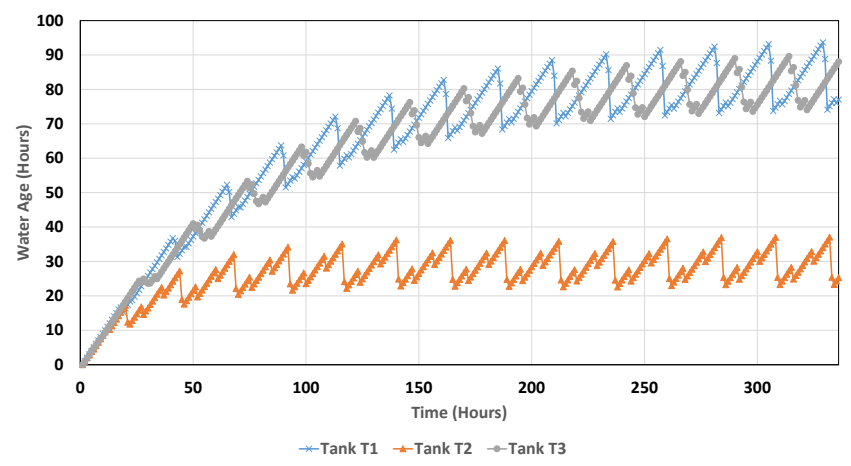

Figure 14 Water age in tanks for maximum operating levels in tanks T-1 and T-3 set at $248 \mathrm{ft}(75.60 \mathrm{~m})$.

\section{Conclusions}

The model described in this paper is a novel approach to optimization of daily pump operation schedules and valve controls considering tank turnover requirements for a WDS. In addition to minimizing the power costs associated with pumping required in a WDS, the model also achieves compliance of the system operations with tank turnover requirements by optimizing the pump and valve operations.

\section{Acknowledgments}

This research is supported by U.S. National Science Foundation (NSF) Project 029013-0010, CRISP Type 2-Resilient Cyber-Enabled Electric Energy and Water Infrastructures Modeling and Control Under Extreme Mega Drought.

\section{References}

AWWA (American Water Works Association). 2002a. Effects of Water Age on Distribution System Water Quality. Washington, DC: U.S. Environmental Protection Agency, Office of Ground Water and Drinking Water Standards and Risk Management Division.

https://www.epa.gov/sites/production/files/2015-09/ documents/2007_05_18_disinfection_tcr_whitepaper_tcr_ waterdistribution.pdf

AWWA (American Water Works Association). 2002b. Finished Water Storage Facilities. Washington, DC: U.S. Environmental Protection Agency, Office of Ground Water and Drinking Water Standards and Risk Management Division.

https://www.epa.gov/sites/production/files/2015-09/documents/2007_05_18_disinfection_tcr_whitepaper_tcr_storage.pdf

Brion, L. M. and L. W. Mays. 1991. “Methodology for Optimal Operation of Pumping Stations in Water Distribution Systems." Journal of Hydraulic Engineering 117 (11): 1551-69.

Broad, D. R., G. C. Dandy and H. R. Maier. 2005. “Water Distribution System Optimization Using Meta Models." Journal of Water Resources Planning and Management 131 (3): 172-80.
Cohen, D., U. Shamir and G. Sinai. 2009. “Optimisation of Complex Water Supply Systems with Water Quality, Hydraulic, and Treatment Plant Aspects." Civil Engineering and Environmental Systems 26 (4): 295-321.

Costa, L. H. M., H. M. Ramos and M. A. H. Castro. 2010. “Hybrid Genetic Algorithm in the Optimization of Energy Costs in Water Supply Networks." Water Science \& Technology: Water Supply 10 (3): 315-26.

https://doi.org/10.2166/ws.2010.194

Eliades, D. 2016. EPANET-MATLIB-Toolkit. Republic of Cyprus: KIOS-Research Center, University of Cyprus. https://www.mathworks.com/MATLIBcentral/filesexchange/25100-kios-research-epanet-MATLAB-tookit/

Ghaddar, B., J. Naoum-Sawaya, A. Kishimoto, N. Taheri and B. Eck. 2015. "A Lagrangian Decomposition Approach for the Pump Scheduling Problem in Water Networks." European Journal of Operational Research 241 (2): 490-501. https://doi.org/10.1016/j.ejor.2014.08.033

Goldman, F. E. and L. W. Mays. 2005. “Water Distribution System Operation: Application of Simulated Annealing." In Water Resources Systems Management Tools, edited by L. W. Mays, ch. 5. New York: McGraw-Hill.

Goldman, F. E., A. B. A. Sakarya and L. W. Mays. 2002. “Optimal Operation of Water Systems." In Urban Water Supply Handbook, edited by L. W. Mays, ch. 12. New York: McGraw-Hill.

Grayman, W. M. and G. J. Kirmeyer. 2000. "Quality of Water in Storage." In Water Distribution System Handbook, edited by L. W. Mays, ch. 11. New York: McGraw-Hill.

Hashemi, S., M. Tabesh and B. Ataeekia. 2014. "Ant-Colony Optimization of Pumping Schedule to Minimize the Energy Cost Using Variable-Speed Pumps in Water Distribution Networks." Urban Water 11 (5): 335-47. https://doi.org/10.1080/1573062X.2013.795233

Kang, D. and K. Lansey. 2010. "Realtime Optimal Valve Operation and Booster Disinfection for Water Quality in Water Distribution Systems." Journal of Water Resources Planning and Management 136 (4): 463-73. https://doi.org/10.1061/(ASCE)WR.1943-5452.0000056

Khatavkar, P. and L. W. Mays. 2017. “Model for Optimal Operation of Water Distribution Pumps with Uncertain Demand Patterns." Water Resources Management 31 (12): 3867-80. https://doi.org/10.1007/s11269-017-1712-8

Khatavkar, P. and L. W. Mays. 2018. "Model for the Realtime Operations of Water Distribution Systems Under Limited Electrical Power Availability with Consideration of Water Quality." Journal of Water Resources Planning and Management 144 (11): 1-8. https://doi.org/10.1061/(ASCE)WR.1943-5452.0001000

Kurek, W. and A. Ostfeld. 2013. “Multi-Objective Optimization of Water Quality, Pumps Operation, and Storage Sizing of Water Distribution Systems." Journal of Environmental 
Management 115 (1): 189-97.

https://doi.org/10.1016/j.jenvman.2012.11.030

Ormsbee, L. E. and K. E. Lansey. 1994. "Optimal Control of Water Supply Pumping Systems." Journal of Water Resources Planning and Management 120 (2): 237-52.

Ozger, S. and L. W. Mays. 2005. “Optimal Location of Isolation Valves in Water Distribution Systems: A Reliability/Optimization Approach." In Water Resources Systems Management Tools, edited by L. W. Mays, ch. 7. New York: McGraw-Hill.

Ramos, J. S. and H. M. Ramos. 2009. "Sustainable Application of Renewable Sources in Water Pumping Systems: Optimized Energy System Configuration." Energy Policy 37 (2): 633-43. https://doi.org/10.1016/j.enpol.2008.10.006

Rao, Z. and E. Salomons. 2007. “Development of a Real-time, Near-Optimal Control System for Water-Distribution Networks." Journal of Hydroinformatics 9 (1): 25-38.

Rossman, L. A. 2000. EPANET 2 User's Manual. Cincinnati, OH: U.S. Environmental Protection Agency.

Sakarya, A. B. and L. W. Mays. 2000. “Optimal Operation of Water Distribution Pumps Considering Water Quality." Journal of
Water Resources Planning and Management 126 (4): 210-20. https://doi.org/10.1061/(ASCE)0733-9496(2000)126:4(210)

Salomons, E., A. Goryashko, U. Shamir, Z. Rao and S. Alvisi. 2007. "Optimizing the Operation of the Haifa-A Water Distribution Network." Journal of Hydroinformatics 9 (1): 51-64. https://doi.org/10.2166/hydro.2006.017

Shamir, U. and E. Salomons. 2008. "Optimal Real-time Operation of Urban Water Distribution Systems Using Reduced Models." Journal of Water Resources Planning and Management 134 (2): 181-5. https://doi.org/10.1061/(ASCE)0733-9496(2008)134:2(181)

U.S. Navy. 1999. Consecutive Water System Guidance Document for Navy Installations. Norfolk, VA: U. S. Navy Office of Chief of Naval Operations. CNO N457.

Walski, T. M. 2000. “Hydraulic Design of Water Distribution Storage Tanks." In Water Distribution Systems Handbook, edited by L. W. Mays, ch. 10. New York: McGraw-Hill. 